\title{
Colon cancer controls versus population controls in case-control studies of occupational risk factors Linda Kaerlev*1,2, Elsebeth Lynge ${ }^{3}$, Svend Sabroe ${ }^{2}$ and Jorn Olsen ${ }^{4}$
}

Address: ${ }^{1}$ Research Unit of Maritime Medicine, University of Southern Denmark, Esbjerg, Denmark, ${ }^{2}$ Department of Epidemiology and Social Medicine, University of Aarhus, Aarhus, Denmark, ${ }^{3}$ Institute of Public Health, University of Copenhagen, Denmark and ${ }^{4}$ The Danish Epidemiology Science Centre, Aarhus University Hospital, Aarhus, Denmark

Email: Linda Kaerlev* - L.Kaerlev@dadlnet.dk; Elsebeth Lynge - Elsebeth@pubhealth.ku.dk; Svend Sabroe - ss@soci.au.dk; Jorn Olsen - jo@soci.au.dk

* Corresponding author

Published: 22 April 2004

BMC Cancer 2004, 4:15
Received: 31 October 2003

Accepted: 22 April 2004

This article is available from: http://www.biomedcentral.com/I47I-2407/4//5

(C) 2004 Kaerlev et al; licensee BioMed Central Ltd. This is an Open Access article: verbatim copying and redistribution of this article are permitted in all media for any purpose, provided this notice is preserved along with the article's original URL.

\begin{abstract}
Background: Since updated population registers do not exist in many countries it is often difficult to sample valid population controls from the study base to a case-control study. Use of patient controls is an alternative option if the exposure experience under study for these patients are interchangeable with the experience for population controls. Patient controls may even be preferable from population controls under certain conditions. In this study we examine if colon cancer patients can serve as surrogates for proper population controls in case-control studies of occupational risk factors.
\end{abstract}

Methods: The study was conducted from 1995 to 1997. Incident colon cancer controls $(N=428)$ aged 35-69 years with a histological verified diagnosis and population controls $(N=583)$ were selected. Altogether $254(59 \%)$ of the colon cancer controls and $320(55 \%)$ of the population controls were interviewed about occupational, medical and life style conditions.

Results: No statistical significant difference for educational level, medical history or smoking status was seen between the two control groups. There was evidence of a higher alcohol intake, less frequent work as a farmer and less exposure to pesticides among colon cancer controls.

Conclusions: Use of colon cancer controls may provide valid exposure estimates in studies of many occupational risk factors for cancer, but not for studies on exposure related to farming.

\section{Background}

Since good quality population registries do not exist in many countries, patient controls are often used to provide exposure data from the study base in case-control studies $[1,2]$. Even where good population registries exist, low response rates for population controls may make patient controls an attractive alternative. The aim of obtaining better symmetry in recall between cases and controls may be another reason for using patient controls.

A case-control study is a design that attempts to capture the relative effect measures in the underlying population over time by using selective sampling from the same population that gave rise to the cases. Sampling of population 
controls requires some kind of register to define the sampling frame. In many countries no such valid registers exist.

The condition for using patient controls to replace population controls is that the exposure experience of interest (including time, duration and intensity) should be interchangeable with the experience for proper population controls, sampled at random from the entire study base. Patients with a disease that is neither caused nor prevented by the exposure under study may sometimes fulfill this criterion.

Hospital controls have been used as controls in several studies [2-4]. Patients with colon cancer have been used as controls in occupational studies of cancer under the assumption that colon cancer has an etiology mainly related to genetic and to dietary factors [3]. High-fat, lowfiber diary, red meat, alcohol, sedentary life style, and presence of first-degree relatives with colorectal cancer, aspirin and non-steroid anti-inflammatory drugs (NSAIDS) have been associated with colon cancer [5]. It is a frequent cancer and the disease will lead to hospitalisation at some point in time for almost all with the disease in many parts of the world [6].

As part of the European multi-centre case-control study of seven rare cancers 'Occupational risk factors for rare cancers of unknown etiology', colon cancer was used as the only control group in Spain, Portugal and Latvia and as a supplementary control group for population controls in Denmark $[3,7,8]$.

This study aimed to investigate whether a bias is introduced by using colon cancer controls instead of population controls in occupational studies of cancer. We used the Danish data of the rare cancer study to see if the colon cancer controls had an exposure experience similar to that of the population controls. We did this for a number of indicators taken from the domains of occupational, medical, social and life style factors. All these exposures were selected before data analyses started.

\section{Methods}

An international multi-centre case-control study was conducted in ten European countries from 1995 to 1997 involving persons aged 35 to 69 years using common data collection instruments $[3,4,7,8]$.

In Denmark, both colon cancer controls and population controls were recruited in order to evaluate the potential selection bias in the use of cancer controls. Four population controls and three to four colon cancer controls were recruited for each case. Both population and colon cancer controls were frequency matched with cases in 5 year age groups by sex and, if possible, geographical region (county) to obtain a balanced data set. The control closest in age to the case was selected. As selected colon cancer controls were removed from the study base if they at review of the histology report did not fulfill the diagnostic and histological criteria, the number of colon cancer controls was slightly less than the number of population controls.

Population controls were sampled at four occasions after the start of case enrolment, the first time in October 1995 and the last time in August 1997. Each cluster included controls for the cases identified during the preceding six months.

The colon cancer controls were defined as histologically verified incident colon cancer patients with topography codes 153.0-153.9 (ICD-O, 1976) or C18.0-C18.9 (ICDO, 1990) and morphology codes 81403,82103 or 82313 . They were enrolled based on repeated requests to local pathology departments every four months $[9,10]$. Frequent screening of regional and national cancer and pathology registers were also done.

\section{Data collection}

The colon cancer patients and population controls received a short introduction letter stating that they were selected as controls for a study of rare diseases and a selfadministered questionnaire asking for a chronological description of all jobs held for more than 6 months since leaving primary school. The persons who accepted to participate filled in and returned the questionnaire together with their consent. If a person did not respond, a reminder was sent by mail after 2 weeks. The interviews were performed by trained interviewers according to a highly structured questionnaire used in all centres. Most of the interviews were done by telephone, but $5 \%$ of the interviews were performed face-to-face due to impaired hearing, severe health problems or if they had no telephone at home.

Information was obtained on socio-economic and demographic factors, educational level, adult height and weight, previous medical conditions and occupational factors. A complete occupational history was recorded for all respondents as well as smoking habits and alcohol consumption up to 5 years before the interview. Questions on alcohol consumption addressed the average daily intake of specific types of alcohol. Total daily alcohol intake was computed from the average alcohol content per liter of each beverage: beer, $40 \mathrm{~g}$; wine, $94 \mathrm{~g}$; aperitif, 145 g; liquor, 317 g. In Denmark a drink (one beer, a glass of wine or spirit) contains approximately 12 grams of alcohol. The study was made in accordance with the 
Table I: Selected characteristics of colon cancer controls and population controls

\begin{tabular}{|c|c|c|c|c|c|c|c|c|}
\hline & \multicolumn{4}{|c|}{ Colon cancer controls } & \multicolumn{4}{|c|}{ Population controls } \\
\hline & $\mathrm{N}$ & $(\%)$ & $\mathrm{n}$ & $(\%)$ & $\mathrm{N}$ & $(\%)$ & $\mathrm{n}$ & (\%) \\
\hline Responders & 254 & $(59)$ & & & 320 & (55) & & \\
\hline Men & & & 153 & $(60)$ & & & 195 & $(6 \mathrm{I})$ \\
\hline Women & & & 101 & $(40)$ & & & 125 & (39) \\
\hline \multicolumn{9}{|c|}{ Age at interview (years) } \\
\hline $35-59$ & & & 125 & $(49)$ & & & 180 & $(56)$ \\
\hline $60-69$ & & & 129 & $(5 \mathrm{I})$ & & & 140 & (44) \\
\hline Mean age, years & & & 58.1 & - & & & 56.7 & . \\
\hline Non-responders & 174 & $(4 I)$ & & & 263 & $(45)$ & & \\
\hline Men & & & 93 & $(53)$ & & & 168 & $(64)$ \\
\hline Women & & & 81 & (47) & & & 95 & (36) \\
\hline \multicolumn{9}{|c|}{ Age at contact (years) } \\
\hline $35-59$ & & & 68 & (39) & & & 114 & $(43)$ \\
\hline $60-69$ & & & 106 & (6I) & & & 149 & (57) \\
\hline Mean age, years & & & 60.1 & - & & & 59.9 & . \\
\hline Total & 428 & $(100)$ & & & 583 & $(100)$ & & \\
\hline
\end{tabular}

requirements of the Danish central and regional ethics committees.

\section{Statistical analysis}

We selected prior to data analysis a number of exposures to represent different aspects of interest: educational, life style, medical and occupational conditions. Three to four exposures were selected within each category including the only suggested protective occupational factor for colon cancer (physical demanding work).

To characterise the differences between colon cancer controls and population controls adjusted odds ratios (ORs) were obtained by unconditional logistic regression with $95 \%$ confidence intervals (CIs) for the following variables: level of education, marital status, smoking status, high versus low alcohol intake, obesity, ever had certain diseases (asthma or dermatitis), ever employed in certain occupations (health care, farmer, working with farm animals), and ever having worked in high temperatures or with certain chemicals (chemicals with hormonal effects or pesticides) [11,12]. All adjusted estimates were obtained from a model that included year of birth and sex, since controls were frequency matched on these variables. Occupational data were analyzed by gender because men and women often perform different tasks within the same occupation or industry. Year of birth was used as a continuous variable [13]. A more detailed adjustment for region did not improve the model. If expected cell counts were less than 5 we performed the analyses using Fishers exact test for stratified analyses included in the software package StatXact with stratification by year of birth (2 levels) and sex [14].

\section{Results}

Of the 428 colon cancer controls and the 583 population controls recruited to the Danish study, 254 colon cancer controls (153 men, 101 women) and 320 population controls (195 men, 125 women) were interviewed (Table $1)$. The response rate for colon cancer controls was $59.3 \%$ (62.2\% for men; $55.5 \%$ for women), and for population controls $54.9 \%$ ( $53.7 \%$ for men; $56.8 \%$ for women).

Table 2 shows a comparison between the two control groups regarding social, life style and medical factors presented as ORs for colon cancer controls. No statistically significant differences in educational level or smoking status were seen. More colon cancer patients than population controls were married or lived together with a partner. The proportion of heavy alcohol drinkers was higher for colon cancer controls than for population controls. Stratified analyses showed, however, that the tendency was seen only among older women and men. No statistical significant difference was seen between the two control groups for diseases such as asthma, dermatitis, and obesity (maximum body mass index ever being $\geq 30$ ), although the estimated OR for obesity was above unity $(1.4,95 \%$ CI $(0.9-2.2))$.

Table 3 outlines occupational work tasks and occupational exposures in the two groups. The only significant difference was a lower proportion of male colon cancer controls ever having worked as a general farmer and as a farmer with animals. No significant differences were seen for working in high temperatures or for occupational use of chemicals with hormonal effects, whereas the occupational use of pesticides was higher in male population 
Table 2: Odds ratios for demographic, life style and medical characteristics in colon cancer controls compared with population controls

\begin{tabular}{|c|c|c|c|c|c|c|c|}
\hline & \multicolumn{2}{|c|}{ Colon cancer controls $(\mathrm{N}=254)$} & \multicolumn{2}{|c|}{ Population controls $(\mathrm{N}=320)$} & \multirow[t]{2}{*}{ Crude OR } & \multirow[t]{2}{*}{ Adjusted OR² } & \multirow[t]{2}{*}{$95 \% \mathrm{Cl}^{2}$} \\
\hline & No. & $\%$ & No. & $\%$ & & & \\
\hline $\begin{array}{l}\text { Educational } \\
\text { status, low }\end{array}$ & 59 & 23 & 89 & 28 & 0.8 & 0.7 & $0.5-1.0$ \\
\hline Living alone & 43 & 17 & 77 & 24 & 0.7 & 0.6 & $0.4-0.9$ \\
\hline Ever smokers & 180 & 71 & 228 & 71 & 1.0 & 1.0 & $0.7-1.4$ \\
\hline Heavy smokers ${ }^{4}$ & 70 & 28 & 88 & 28 & 1.0 & 0.9 & $0.7-1.3$ \\
\hline Alcohol, high 5 & 108 & 43 & 98 & 31 & 1.7 & 1.8 & $1.2-2.5$ \\
\hline -Age $35-59$ & 48 & & 59 & & 1.3 & 1.3 & $0.8-2.2$ \\
\hline -Age 60-69 & 60 & & 39 & & 2.3 & 2.3 & $1.4-3.9$ \\
\hline Obesity ${ }^{6}$ & 51 & 20 & 53 & 17 & I.4 & $\mathrm{I} .4$ & $0.9-2.2$ \\
\hline Asthma & 15 & 6 & 28 & 9 & 0.7 & 0.6 & $0.3-1.2$ \\
\hline Dermatitis & 47 & 19 & 62 & 19 & 0.9 & 0.9 & $0.6-1.4$ \\
\hline
\end{tabular}

I Crude odds ratio (OR). ${ }^{2}$ OR with $95 \%$ confidence interval $(\mathrm{Cl})$, adjusted for sex and age. If expected values were less than 5 , Fishers exact test was used with stratification by year of birth ( 2 levels) and sex. ${ }^{3}$ Left school at 15 y no further education. ${ }^{4}$ More than 20 pack-years ('pack-years' $=$ number of years as a smoker $*$ number of cigarettes per day/20). ${ }^{5}$ Total alcohol intake $>24$ grams alcohol per day. ${ }^{6}$ Obesity defined as maximum body mass index ever being $\geq 30$.

Table 3: Odds ratios for occupational characteristics in colon cancer controls compared with population controls

\begin{tabular}{|c|c|c|c|c|c|c|c|}
\hline \multirow[b]{2}{*}{ Occupation } & \multicolumn{2}{|c|}{ Colon cancer controls $(\mathrm{N}=254)$} & \multicolumn{2}{|c|}{ Population controls $(\mathrm{N}=320)$} & \multirow[t]{2}{*}{ Crude ORI } & \multirow{2}{*}{$\begin{array}{l}\text { Adjusted } \\
\mathrm{OR}^{2}\end{array}$} & \multirow[t]{2}{*}{$95 \% \mathrm{Cl}^{2}$} \\
\hline & No. & $\%$ & No. & $\%$ & & & \\
\hline \multicolumn{8}{|l|}{ Health care ${ }^{3}$} \\
\hline$-M e n^{4}$ & 4 & 3 & 3 & 2 & 1.8 & 1.9 & $0.4-8.8$ \\
\hline -Women ${ }^{4}$ & 18 & 18 & 21 & 17 & 1.1 & I.I & $0.5-2.1$ \\
\hline -Both sexes & 22 & 9 & 24 & 8 & 1.2 & 1.2 & $0.6-2.3$ \\
\hline \multicolumn{8}{|l|}{ Farming ${ }^{3}$} \\
\hline$-M_{e n}^{4}$ & 23 & 15 & 48 & 25 & 0.6 & 0.5 & $0.3-0.9$ \\
\hline -Women ${ }^{4}$ & 7 & 7 & 4 & 3 & 2.3 & 2.1 & $0.6-7.6$ \\
\hline -Both sexes & 30 & 12 & 52 & 16 & 0.7 & 0.7 & $0.4-1.1$ \\
\hline \multicolumn{8}{|l|}{ Farming animals ${ }^{3}$} \\
\hline$-M_{e n}^{4}$ & 20 & 13 & 48 & 25 & 0.5 & 0.4 & $0.2-0.8$ \\
\hline -Women ${ }^{4}$ & 5 & 5 & 3 & 2 & 2.1 & 2.0 & $0.5-8.9$ \\
\hline -Both sexes & 25 & 10 & 51 & 16 & 0.6 & 0.5 & $0.3-0.9$ \\
\hline \multicolumn{8}{|l|}{ High temperatures ${ }^{5}$} \\
\hline$-M^{4}{ }^{4}$ & 17 & 11 & 29 & 15 & 0.7 & 0.7 & $0.4-1.4$ \\
\hline -Women ${ }^{4}$ & 5 & 5 & 7 & 6 & 0.9 & 0.9 & $0.3-3.0$ \\
\hline -Both sexes & 22 & 9 & 36 & 11 & 0.8 & 0.8 & $0.4-1.3$ \\
\hline \multicolumn{8}{|l|}{ Chemicals hormonal effects 6} \\
\hline$-M^{4}$ & 6 & 4 & 15 & 8 & 0.5 & 0.5 & $0.2-1.3$ \\
\hline -Women ${ }^{4}$ & 6 & 6 & 6 & 5 & 1.3 & 1.3 & $0.4-4.1$ \\
\hline -Both sexes & 12 & 5 & 21 & 7 & 0.7 & 0.7 & $0.3-1.5$ \\
\hline \multicolumn{8}{|l|}{ Pesticides ${ }^{7}$} \\
\hline$-M e n^{4}$ & 12 & 8 & 33 & 17 & 0.4 & 0.4 & $0.2-0.8$ \\
\hline -Women ${ }^{4}$ & 3 & 3 & 3 & 2 & 1.3 & 1.3 & $0.3-6.5$ \\
\hline -Both sexes & 15 & 6 & 36 & 11 & 0.5 & 0.5 & $0.3-0.9$ \\
\hline -Adjusted for farm work & - & & - & & - & 0.6 & $0.3-1.2$ \\
\hline
\end{tabular}

I Crude odds ratio (OR). 2 OR with $95 \%$ confidence interval (Cl), adjusted for year of birth and age. If expected values were less than 5 , Fishers exact test was used with stratification by year of birth ( 2 levels) and sex. ${ }^{3}$ Ever working in these occupations. ${ }^{4}$ OR with $95 \%$ confidence interval (Cl) adjusted for year of birth. If expected values were less than 5 , Fishers exact test was used with stratification by year of birth ( 2 levels). ${ }^{5}$ Ever working in high temperatures. ${ }^{6}$ Ever working with chemicals with hormonal effects. ${ }^{7}$ Ever working with pesticides. 
controls. When this analysis was adjusted for farm work no statistical significant difference was seen, although the estimated OR remained below unity $(0.6,95 \%$ CI $(0.3-$ 1.2)).

\section{Discussion}

Colon cancer controls had rather similar characteristics as population controls for most of the occupational exposures under study except for work with farm animals, use of pesticides, and for certain life style related factors such as high alcohol intake. The difference in the frequency of farming between the two sets of controls may be caused by a possible protective effect of physical activity for colon cancer. The study does not prove that colon cancer patients are valid surrogates for population controls in some situations. Small to moderate true differences in the exposure experience between colon cancer controls and population controls cannot be ruled out as indicated by the confidence limits of the ORs. The study only documents that the bias associated with using colon cancer controls rather than population controls in studies of occupational risk factors for cancer in some cases is small or non-existing except for studies on exposures related to farming. An acceptable level of difference between the exposure experience of interest depends not only on the aim of the study but also of the effect of the exposure under study.

The proportion of non-responders was rather high but similar in the two groups $(41 \%$ in the colon cancer controls and $45 \%$ in population controls), which is in contrast to the expectations that the response rate should be higher among patient controls. The reason could be that both groups were contacted at home by telephone.

Colon cancer controls were patients whereas most population controls were non-patients which may create an asymmetry in recall of exposure [15]. We only expect this problem to be of relevance for sensitive questions such as alcohol intake and for questions that require recall over longer time periods.

The statistically significant difference for alcohol may indicate that this is a risk factor for colon cancer. The difference for work as a farmer and work with farm animals may indicate that these job tasks protect against colon cancer. Both findings are in line with the existing literature [16]. A negative association between use of pesticides and colon cancer was seen but the significant association disappeared when the analysis was adjusted for farm work, although the OR was still low. This may be due to residual confounding, chance or that pesticides prevent colon cancer. The association between farm work and colon cancer in many studies call for caution when using colon cancer patients as controls in studies related to farm work, since we do not know what elements of farm work prevents colon cancer [17]. The assumption is that it is physical activity but that is still just a hypothesis. If the exposures under study cause or prevent the disease in question, patients with this disease constitute an unsuitable control group for producing valid quantitative effect measures for these specific exposures [18].

Other studies have outlined benefits and limitations of using different kinds of control groups in different situations [19-23]. The perfect control group is easy to define but difficult to get. Population controls should in most cases be the first choice, if possible, since only they provide the sample from the study base we want.

\section{Conclusions}

The present study shows, that colon cancer patients have many similar characteristics as a population sample and may be used as controls in certain case-control studies of occupational risk factors for cancer, at least in countries with a similar industrial structure and similar life style as in Denmark. Our study aimed to investigate the use of colon cancer controls in occupational studies of cancer. In these studies it is advisable to control for factors we found to correlate with colon cancer risk (such as obesity) whether our associations were statistically significant or not. If these factors change the effect measures under study they should be adjusted for. Cancer studies on exposures that are suggested to prevent colon cancer e.g. farming or cause colon cancer e.g. alcohol intake should not use colon cancer controls. Use of colon cancer controls in these cases may lead to biased effect measures.

\section{Competing interests}

None declared.

\section{Authors' contributions}

All authors (LK, EL, SS, JO) participated in the design and coordination of the study.

LK performed the statistical analysis and drafted the manuscript.

All authors read, commented and approved the manuscript.

\section{Acknowledgments}

We gratefully acknowledge collaboration from patients, control persons, participating hospitals, and data providers. "Occupational risk factors for rare cancers of unknown aetiology" was supported financially by the European Commission, DGXII, Programme BIOMED, grant no BMHI CT 931630, and national funding agencies in Denmark: The strategic Environment Programme, grant no 92.01.015.7-06, and the Danish Epidemiology Science Centre, whose activities are financed by a grant from the Danish National Research Foundation. Torben and Alice Frimodt Foundation, BeckettFoundation, Direktør Jacob Madsen and Olga Madsen Foundation, Civil 
engineer Bent Bøgh and Inge Bøgh Foundation, Else and Mogens WedellWedellsborg Foundation, Carl and Ellen Hertz Foundation, Aarhus Social Medicine Research Foundation.

\section{The Danish Study Group on Occupational Causes of Rare Cancers}

(Herman Autrup, Henrik Kolstad, Linda Kærlev, Elsebeth Lynge, Jorn Olsen, Lisbeth Norum Pedersen, Svend Sabroe, Reference pathologists:

Preben Johansen, Stein Poulsen, Peter Stubbe Teglbjærg, Mogens Vyberg).

\section{References}

I. Mannetje A, Kogevinas M, Chang-Claude J, Cordier S, Gonzalez CA, Hours M, Jockel KH, Bolm-Audorff U, Lynge E, Porru S, Donato F, Ranft U, Serra C, Tzonou A, Vineis P, Wahrendorf J, Boffetta P: Occupation and bladder cancer in European women. Cancer Causes Control 1999, 10:209-217.

2. No authors listed: Effect of different progestagens in low oestrogen oral contraceptives on venous thromboembolic disease. World Health Organization Collaborative Study of Cardiovascular Disease and Steroid Hormone Contraception. Lancet 1995, 346:1582-1588.

3. Kaerlev L, Teglbjaerg PS, Sabroe S, Kolstad HA, Ahrens W, Eriksson M, Gonzalez AL, Guenel P, Hardell L, Launoy G, Merler E, Merletti F, Suarez-Varela MM, Stang A: Occupation and small bowel adenocarcinoma: a European case-control study. Occup Env Med 2000, I I:760-766.

4. Kaerlev L, Lynge E, Sabroe S, Olsen J: Reliability of data from next-of-kin: results from a case-control study of occupational and lifestyle risk factors for cancer. Am J Ind Med 2003, 44:298-303.

5. Boyle P, Langman JS: ABC of colorectal cancer: Epidemiology. BMJ 2000, 321:805-808.

6. No authors listed: Cancer Incidence in Five Continents Volume VII. IARC Sci Publ; 1997.

7. Morales Suarez-Varela MM, Olsen J, Kaerlev L, Guenel P, Arveux P, Wingren G, Hardell L, Ahrens W, Stang A, Llopis-Gonzalez A, Merletti F, Guillen-Grima F, Johansen P: Are alcohol intake and smoking associated with mycosis fungoides? A European multicentre case-control study. Eur / Cancer 2001, 37:392-397.

8. Kaerlev L, Teglbjaerg PS, Sabroe S, Kolstad HA, Ahrens W, Eriksson M, Guenel P, Hardell L, Launoy G, Merler E, Merletti F, Stang A, Olsen $\mathrm{J}$ : Is there an association between alcohol intake or smoking and small bowel adenocarcinoma? Results from a European multi-center case-control study. Cancer Causes Control 2000, II:79I-797.

9. World Health Organization: International Classification of Diseases for Oncology Geneva: World Health Organization; 1976.

10. Percy C, Van Holten V, Muir C, eds: International Classification of Diseases for Oncology Geneva: World Health Organization; 1990.

II. Chan IS: Proving non-inferiority or equivalence of two treatments with dichotomous endpoints using exact methods. Stat Methods Med Res 2003, I 2:37-58.

12. Garrett AD: Therapeutic equivalence: fallacies and falsification. Stat Med 2003, 22:74|-762.

13. Brenner $\mathrm{H}$, Blettner M: Controlling for Continuous Confounders in Epidemiologic Research. Epidemiology 1997, 8:429-434.

14. Cytel Software Corporation: StatXact 5. Cambridge: MA 2001.

15. Drews $C D$, Greeland $S$ : The impact of differential recall on the results of case-control studies. Int J Epidemiol 1990, 19:II07-III2.

16. Slattery ML, Edwards SL, Boucher KM, Anderson K, Caan B]: Lifestyle and colon cancer: an assessment of factors associated with risk. Am J Epidemlol 1999, I 50:869-877.

17. Ronco G, Costa G, Lynge E: Cancer risk among Danish and Italian farmers. $\mathrm{Br} J$ Ind Med 1992, 49:220-225.

18. Miller AB: Hospital or population controls? It depends on the question. Prev Med 1994, 23:263-266.

19. Agudo A, Gonzalez CA: Secondary matching: a method for selecting controls in case-control studies on environmental risk factors. Int J epidemiol 1999, 28: I I 30-I I33.

20. Gonzalez CA, Torrent M, Agudo A, Riboli E: Hospital versus neighbourhood controls in the assessment of dietary risk factors. Int J Epidemiol 1990, 19:354-36I.
21. Wacholder S, Silverman DT, McLaughlin JK, Mandel JS: Selection of controls in case-control studies. I. Principles. Am J Epidemiol 1992, 135:1019-1028.

22. Wacholder S, Silverman DT, McLauglin JK, Mandel JS: Selection of controls in case-control studies. II. Types of controls. Am J Epidemiol 1992, 135:1029-104I.

23. Miettinen OS: The "case-control" study: valid selection of subjects. J Chronic Dis 1985, 38:543-548.

\section{Pre-publication history}

The pre-publication history for this paper can be accessed here:

http://www.biomedcentral.com/1471-2407/4/15/prepub
Publish with Bio Med Central and every scientist can read your work free of charge

"BioMed Central will be the most significant development for disseminating the results of biomedical research in our lifetime. "

Sir Paul Nurse, Cancer Research UK

Your research papers will be:

- available free of charge to the entire biomedical community

- peer reviewed and published immediately upon acceptance

- cited in PubMed and archived on PubMed Central

- yours - you keep the copyright

Submit your manuscript here:

http://www.biomedcentral.com/info/publishing_adv.asp
BioMedcentral 